\title{
İşyeri Mutluluğu: Bir Kavram İncelemesi
}

\author{
DOI: 10.26466/opus.883377 \\ *
}

\author{
Tuğba Erhan* \\ * Dr. Öğr. Üyesi, Süleyman Demirel Üni., İktisadi İdari Bilimler Fakültesi, Isparta/Türkiye \\ E-Posta: tugbaerhan@sdu.edu.tr \\ ORCID: $\quad$ 0000-0002-5697-490X
}

\begin{abstract}
Öz
Çalışan bireyler hayatlarının büyük bir çoğunluğunu işyerinde geçirmektedir. Dolayısıyla işyerinde yaşadıkları olaylar bireylerin işyeri dışındaki yaşamlarını da doğrudan etkileyebilmektedir. Bireyler çalıştıklar işyerlerinde mutlu hissettikleri zaman bu durum çalışanların örgüt için verimliliklerini arttıracak ayrıca işyeri dışında geçirdikleri zamanlarında da iyi oluş ve yaşam tatmini düzeylerini de geliştirebilecektir. Günümüz örgütlerinin çoğu işyeri mutluluğu yüksek çalışanları sayesinde daha sürdürülebilir bir üretkenliğe sahip olabileceklerinin farkındadır. Ancak bu farkındalığın işyerindeki bireylerin mutlulukların nasıl arttırabileceği konusundaki faktörlerin yalnızca incelenmesi değil aynı zamanda düzenli bir şekilde uygulanması da önemlidir. İsyeri mutluluğu kavramı pozitif psikoloji disiplininin uğraş alanında sıkla incelenmekte iken aynı zamanda yönetim ve örgütsel davranış alanında da araştırılmaya devam etmektedir. Çıkış noktası temel mutluluk olan işyeri mutluluğu kavramı teorik olarak pozitif psikolojinin öncüsü Martin Seligman'ın mutluluğun esasların ortaya koyduğu çalışmalarılyla da güçlenmiştir. Bireylerin genel mutluluk düzeyi iş yaşamlarına da yansımaktadır. Dolayısıyla birey iş ve yaşam arasındaki dengeyi sahip olduğu olumlu duygular ile daha kolay sağlayabilecektir. Bu sebeple, örgütler de işyerinde geçirdikleri zamanın fazlalığını göz önünde bulundurarak motivasyonu yüksek çalışanlara sahip olmak için işyeri mutluluğunun nasıl arttırılabileceği konusunda çaba göstermektedir. Bu çabanın sonucu olarak hem bireysel hem örgütsel olumlu iş çıtılları elde etmek mümkündür. Bu çalışma ile işyeri mutluluğun hem örgüt çalışanları hem de örgütler açısından önemini kavramsal bir şekilde öncül ve ardıl faktörler ile ortaya koymak amaçlanmaktadır.
\end{abstract}

Anahtar Kelimeler: Mutluluk, İşyeri Mutluluğu, İş Çıktıları, Öncüller, Ardıllar. 


\title{
Workplace Happiness: A Concept Analysis
}

*

\begin{abstract}
Working individuals spend most of their lives at work. Thus, events experienced in the workplace can directly influence the individuals' lives outside the workplace. When individuals feel happy in the workplace, this will increase the productivity of the employees for the organization and also improve their well-being and life satisfaction levels during the times spent outside the workplace. Most of today's organizations are aware of having employees with high workplace happiness will have more sustainable productivity. However, it is important not only to examine the factors on how to increase the workplace happiness of the individuals but also to apply them on a regular basis. While the concept of workplace happiness is frequently examined in the field of positive psychology discipline, it also continues to be investigated in the field of management and organizational behavior. Based on general happiness, the term "workplace happiness" has been strengthened theoretically with the studies of the pioneer of positive psychology Martin Seligman who put forward the principles of happiness. The general happiness level of individuals has reflections on their work life. Therefore, the individual will be able to achieve the balance between work and life more easily with his/her positive emotions. For this reason, organizations strive on how to increase workplace happiness in order to have highly motivated employees, taking into account the amount of time they spend in the workplace. As a result of this effort, it is possible to obtain positive work outcomes both for individual and organizational level. In this study, it is aimed to reveal the importance of the term workplace happiness for both the employees and organizations by reviewing the term with its antecedents and consequences factors.
\end{abstract}

Keywords: Happiness, Workplace Happiness, Positive Work Outcomes, Antecedents, Consequences 


\section{Giriş}

Mutluluk kavramı pozitif psikoloji değişkenleri arasında sıkça kullanılan insan davranışlarının güçlü yanlarının beslenerek nasıl daha iyi açıklanabileceği yönünde araştırmalar ile gündeme gelmektedir. Uzun zamandır pozitif psikoloji ve son yıllarda örgütsel davranış ve yönetim disiplinlerinin de incelediği bu kavram bireylerin davranışlarının, çabalarının ve emeklerinin sonrasında varmak istedikleri nihai durak olarak da belirtilebilir. Bireyler yaşamları süresince birbirinden farklı hedefler peşinde koşabilir. Ancak farklı hedef türleri şeklinde de olsa örneğin bir hedefin gerçekleşmesi diğer bir hedefin gerçekleşmesine bağlı olsa, tek bir hedef takibi ya da aynı anda birden fazla hedef takibi de olsa (Locke ve Latham, 1990) sonucunda söz konusu hedeflerin gerçekleşmesi durumunda bireyler mutluluğu yakalayacakları kanısındadır. Pozitif psikolojinin olumlu değişkenler sıralamasında mutluluk kavramı çoğu zaman bireylerin hayatlarının bilişsel ve duyuşsal değerlendirmelerini (Diener, 2000) ifade eden öznel iyi oluş/iyilik hali (subjective well-being) kavramı ile bağdaştıılmaktadır (Luthans, 2002; Diener, 2000). Bahsi geçen "öznel" kelimesi burada bireylere "mutlu ol" denildiğinde olamayabileceklerini, dolayısıyla hem mutluluğun bireyden bireye farklılaştığını hem de Aristoteles'in ifadesiyle mutluluğun bir erdem (virtue) olduğunun altını bir kez daha çizmektedir (Myers ve Diener, 1995).

Tarihsel akışta kökeni eskilere dayanan pozitif psikolojinin kurucusu olarak kabul gören Martin Seligman (2002); bireylerin baş etmekte zorlandığı olumsuz duygu durumlarının esasen bireylerin güçlü yanlarının öne çıarılarak azalacağını hatta kaybolacağını ifade etmektedir. Öte yandan Seligman (2002); Gerçek mutluluk (Authentic Happiness) isimli kitabında, bireylerin olumlu duygulara yönlendirilmeleri konusuna ve bu olumlu duyguları tecrübe etme sıklıklarının arttırılmasına/geliştirilmesine yönelik ifadelerinde, tüm ilişkilerin temelinde olumlu duygulara sahip olmanın yer aldığını ve aynı zamanda bu duyguları açığa çıkarmanın da önemli olduğuna dikkat çekmektedir.

Bireylerin nasıl mutlu oldukları ve hangi mutluluk kaynaklarından beslendikleri farklılaşabilmektedir. Mutluluk yönelimlerinin bir kısmını 
hayattan zevk almak şeklinde amaç edinen bireylerin yanı sıra bazı bireyler mutluluğu "anlam arayışı" olarak da algılayabilmektedir (Peterson vd., 2005). Bu anlam arayışı Seligman (2002)'ın gerçek mutluluk modelinde yer alan keyifli hayat, hayata bağlllık ve anlamlı hayat gibi üç mutluluk türü ile de örtüşmektedir. Ayrıca yapılan çalışmalar mutluluk kavramının işyeri kökenli olduğunun önemini vurgulayarak mutlu çalışanlara sahip olmanın örgüt adına özellikle üretkenlik artışı gibi olumlu iş sonuçları sağladığını ortaya koymaktadır (Wright ve Staw, 1999; Gregory, 2011). Sözü edilen örgütsel iş çıtılarının oluşumunda bireylerin mutluluk düzeylerinin davranışlarına da olumlu yansımaları olduğu ifade edilmiştir (Joo ve Lee, 2017). Dolayisıyla bu olumlu duygunun geliştirilmesi aynı zamanda uzun süreli olması örgütsel davranış ve yönetim disiplinlerinde de mutluluk üzerine yapılan çalışmaların artışına sebep olmuştur (Chiumento, 2007; Abraham, 2015; Bani-Melhem vd., 2018).

İşyeri mutluluğu ile ilgili çalışmalar ulusal ve uluslararası alan yazında giderek artan bir şekilde araştırılmaktadır. Ancak bütüncül olarak ele alan yerli yazında kavramsal bir çalışmanın yapılmasının ulusal yazına katkı sağlayacağı düşünülmektedir. Son yirmi yıl içerisinde yapılan çalışmaların odak noktası mutlu çalışanların işyeri verimliliğini arttırdığını yönünde sonuçları ortaya koymaktadır (Wright ve Staw, 1999; Judge vd., 2001; Quick ve Quick, 2004).

Anahtar kelimeler tekniği (Köroğlu, 2015: 64) kullanılarak yapılan bu çalışmada ilk olarak kavramın tanımı ve teorik temelleri ele alınmıştır. İlerleyen bölümlerde kavramın boyutlandırılması, öncül ve ardılları ile işyeri mutluluğunun örgütler açısından önemi ve nasıl geliştirilebileceği üzerine öneriler ile tamamlanmıştır.

\section{İşyeri Mutluluğunun Kavramsal Çerçevesi}

\section{a. İşyeri Mutluluğu Kavramı ve Teorik Alt Yapısı}

Olumlu duyguların inşa edilmesi, geliştirilmesi ve nihai amaç olarak elde edilmesi amaçlanan mutluluk kavramı çoğu bireyin peşinde koştuğu bir duygu halidir. Karşılaşılan durumların algılanma biçimi, kişilik özelliği, tutumlar ve içsel ya da dişsal pekiştireçler ile şekillenen mutluluğu 
yaşama/hissetme sonucu hayattan, sosyal çevreden ve sahip olunan işlerden elde edilen tatmin düzeyi bireyden bireye değişiklik gösterebilmektedir. Hayatta kalmak, daha iyi bir yaşam standardına sahip olmak ya da mesleğe duyulan bağlılık gibi çeşitli sebeplerle bireyler çalıştıkları işlerini sürdürmeye çaba göstermektedir. Özellikle son yılların küresel krizlerinin her alanda zorlaştırdığ 1 refah yaşam sürme süreci giderek daha fazla çalışma saatleri, tatil günlerinin azalması ve ekonomik döngünün içerisinde kalabilme ihtiyacını güçleştirmektedir. Bu güçlükler karşısında bireyler daha çok çalışmakta ve hayatlarının neredeyse tamamını iş yerlerinde geçirmek zorunda kalabilmektedir. Bu yoğun iş temposuna ve bireylerin yaşamlarının büyük bir çoğunluğunu işyerinde geçirdiklerine örnek olarak nüfus yoğunluğunun oldukça kalabalık ve iş gücünün ucuz olduğu Çin'deki çalışma prensibi örnek gösterilmektedir (Zhang, 2020). 996 çalışma rejimi (996 work regime) olarak bilinen, çalışanların sabah 9'dan akşam 9'a ve 6 gün boyunca ek bir ödeme almaksızın çalıştıklarını ifade eden bu sistem sonrası olumsuz iş çıktıları ile karşılaşmak kaçınılmazdır. Ancak küresel bazda üretim zincirinin içerisinde yer alabilme çabası/rekabeti çalışma saatlerinin arttırılmasına ve sonuç olarak işgörenlerin işyerlerinde daha fazla zaman geçirmesine neden olmaktadır. Örgütler işgörenlerin işlerini bırakmalarını ve bu arada oluşacak zaman kaybını maddi bir kayıp olarak değerlendirdikleri için işgörenleri mümkün olduğunca uzun süre işyerinde, örgütsel bağlılıkları yüksek şekilde tutmayı amaçlamaktadır. Örgütler işyerinde mutlu çalışanlara sahip olduklarında aynı zamanda iş performansı yüksek (Fredrickson, 2003) bireyler ortaya çıacak ve bu durum örgütlere bütünleşik bir rekabet avantajı sağlayarak işten ayrılma durumlarını da minimum düzeye düşürecektir. Dolayısıyla, örgütler çalışanlarının hayatlarının göz ardı edilemeyecek bir bölümünü işyerinde geçirdikleri gerçeğinden yola çıkarak güvenli, refah, huzurlu ve değerli hissettiren bir işyeri ortamı oluşturma konusunda çeşitli adımlar atmaktadır. Öte yandan mutlu çalışanların varlığının mutlu örgütler ile direk olarak bağdaştırılması da (Simmons, 2014) örgüt çalışanlarının işyerinde mutlu hissetmelerinin önemini vurgulamaktadır. Bu duruma ek olarak örgüt çalışanlarının örgütlerine duygusal olarak bağlı hissetmelerinde ve kendilerini değerli hissetmelerinde işyeri ortamındaki mutlu ya da mutsuz duygu durumları önemlidir. 
Örgüt çalışanları yalnızca görevleri yerine getirmekle yükümlü iş gücü olarak değil duygusal ve düşünsel algılamaları olan bireyler olduklarını hissettiklerinde çalıştıkları örgüte karşı minnet duygusu geliştirecek ve bu durum iyi oluşlarını/mutluluklarını arttıracaktır (Fredrickson, 1998). Bununla birlikte, zamanlarının büyük çoğunluğunu işyerlerinde geçiren çalışanlar için "işyerleri" olumlu duyguların tecrübe edildiği/yaşandığg ve bu olumlu tecrübelerin etkilerinden fayda elde edilebilmesi açısından paha biçilmez fırsatlar sağlayan ortamlardır (Stairs ve Galpin, 2010).

Edmunds ve Pryce-Jones (2008); iş yeri mutluluğunu bireylerin sahip olduğu kaynakları en iyi şekilde farkındalıkla kullanma ve karşılaşılan zorlukların üstesinden gelme durumu şeklinde tanımlamaktadır.

Mutlu birey çoğunlukla olumlu duyguları yaşayan/tecrübe eden birey olarak tanımlanırken (Boehm ve Lyubomirsky, 2008); Haller ve Hadler (2006, s.172-174); mutluluk kavramını aşağıda belirtilen,

1. Bireylerin değişmeyen kişilik özelliği

2. Tarafsız yaşam sürmenin bir sonucu

3. Bireylerin fayda sağladıkları bir kaynak

4. Diğer bireylerle karşılaştırmanın sonucu oluşan görece tatmin süreçleri

5. Kalıcı ulusal veya kültürel özellik olduğu ifade edilen beş teorik yaklaşım ile açıklamaktadır.

Sözü edilen mutluluk teorilerinin yanı sıra mutluluğun iş performansı ile ilgili olduğunu ileri süren bir çalışma mutlu çalışanlar ile mutsuz çalışanlar arasındaki farkın işyerine yansımalarını ele almaktadır (Cropanzano ve Wright, 2001). Mutlu ve mutsuz çalışanların işyerindeki psikolojik durumlarını ortaya koyan bu çalışmada; mutsuz bireylerin iş ortamında oluşabilecek risklere karşı daha duyarlı, iş arkadaşlarına karşı daha savunmacı ve tedbirli ayrıca daha az iyimser ve daha az özgüvenli olduklarını belirtmektedir. Mutlu çalışanlar ise; iş ortamlarında/çevrelerinde oluşabilecek fırsatlara karşı daha duyarlı, iş arkadaşları ile daha dışa dönük/sosyal ve yardımsever ve son olarak daha fazla iyimser ve öz güvenli olmaktadır (Cropanzano ve Wright, 183- 184: 2001). Sözü edilen mutlu çalışanların mutluluk düzeylerinin etkilerinin belirlenebilmesi ve ölçülebilir olması da örgütlerin çalışanlarının iyi oluş durumları hakkında bilgi edinebilmelerine ışık tutabilecektir. 
Martin Seligman (2011) iyi oluş ve çalışanların mutluluklarının ölçülebilir belirli bileşenlerinin olduğunu ileri sürdüğü PERMA modelinde, olumlu duygular, bağlanma, anlam, olumlu ilişkiler ve başarı kavramlarından söz etmektedir. Kavramların baş harflerinin kısaltmalarından oluşan model, bireylerin mutluluklarının tek bir şarta bağlı olmadığının farklı birçok duygu durumunun etkisi ile oluştuğunun altını çizmektedir. Perma modelinin ışık tuttuğu mutluluk kavramının bileşenlerine ek olarak işyeri mutluluğu kavramını farklı teoriler ile birleştirerek açıklamak mümkündür. Olumlu Duyguları Genişletme ve İnşa Etme Teorisi'ne göre (Fredrickson, 2001); bireyler olumlu duygu durumuna sahip olduklarında, düşünce ve bakış açılarında yaratıcılık elde eder ve yeni keşifleri doğrultusunda olumlu ilişkiler kurabilir ve olumlu duygu halinin sürekliliğini kolaylaştırabilirler. Bu teori PERMA modelinin bağlanma bileşeni ile de uyuşmaktadır. Bireyler mutlu hissettiklerinde iş arkadaşları ile dostluk ilişkilerini geliştirebilir ve takım halinde hareket etme duygusu ile mutlu hissedebilirler.

Öte yandan, Öz-Belirleme Teorisi (Ryan ve Deci, 2009; bireylerin iyi oluş hallerinin yüksek olmasını özerklik, yeterlik ve ilişkili olma gibi psikolojik gereksinimler ile açıklamaktadır. Birey bu gereksinimlerini karşılaması durumunda bir başka deyişle, işyerinde kendi kararlarını verme konusunda baskı altında hissetmemesi, işleri yerine getirme konusunda kendisini yeterli hissetmesi ve çevresi ile iyi ilişkiler/bağ kurabilmesi iyi oluş durumlarını olumlu yönde etkilemektedir (Lyubomirsky ve Layous, 2013). Suojanen (2012) işyeri mutluluğu kavramının teorik altyapısını vurguladığı yüksek lisans tezinde işyeri mutluluğunun durum odaklı ve birey odaklı iki teorisinden söz etmektedir. Durum odaklı (situation-oriented) işyeri mutluluğu teorisi; işyeri ortamında gerçekleşen süreçlerin/faktörlerin ve grup içi dinamiklerin mutluluğa yansımalarını içermektedir. Birey odaklı (individual-oriented) işyeri mutluluğu teorisi ise; bireysel mutluluk için atfedilen bilişsel faktörler, tutumlar ve bireysel yeterlilikleri ifade etmektedir. Waal (2018); örgütsel çekiciliğin arttırılmasında işyeri mutluluğunun etkisini incelediği çalışmasını birey odaklı işyeri mutluluğu teorisine dayandırmaktadır. Bu çalışmada, bireysel mutluluk arttıkça örgütün çekiciliğinin de arttığı vurgulanmaktadır. Batı dünyasında özellikle bireylerin iyi bir yaşam sürme hedeflerinin 
içeriklerinden biri olan mutluluk yaşamdan keyif alma, ihtiyaçlarını karşılayabilme, başarılar elde etme, kişisel yeterliliklerinin farkına varıp bunları geliştirebilme, insan doğası ile uyumlu hayat sürebilme gibi isteklerin tatminini ifade etmektedir (Sumner, 1996). Öznel yaşam doyumu ile ilişkilendirilen mutluluk kavramı bireylerin hayatları hakkındaki olumlu ya da olumsuz bilişsel yargıları içermektedir (Griffin, 1985). Suikkanen (2011) bu yargıların geçmiş, şimdiki ve beklenen gelecek ile değerlendirmelerini ve başkalarının mutluluk bakış açıları ile karşılaştırılmasını yapıp mutluluk kavramını Bütün Yaşam Doyumu Teorilerini inceleyerek ortaya koymaya çalışmaktadır. Mutluluğun psikolojik temelli altyapısı üzerinde duran Haybron (2013); mutluluk bileşenlerinden söz ederken kendini gerçekleştirme kavramını vurgulamaktadır. Bu bileşen aynı zamanda Maslow (1943) İhtiyaçlar Hiyerarşisi Teorisi ile de örtüşmekte ve bireylerin kendini gerçekleştirme süreçlerinde elde ettikleri başarıyla mutlu olabileceklerini ifade etmektedir.

Mutluluk kavramının farklı teoriler ve bileşenler ile açılanabilir olmasının yanı sıra mutluluğa etki eden faktörlerin de günümüz beklenmedik krizlerine maruz kalmasının sonucunda özünde nihai amaç olan mutluluğun farklı gereksinimlerin giderilmesi ile elde edilebileceği ileri sürülmektedir. Örneğin; Gavin ve Mason (2004) işyerinde mutluluğun önemini vurguladığı diğer bir çalışmada maddi ve manevi açıdan daha iyiye sahip olmanın temelinde çok çalışmanın olduğunu ve hayali kurulan her ne varsa bunun bireylerin yaptıkları "işler" aracılığıyla gerçekleşebileceğini belirtmiştir. Başka bir deyişle bireylerin hayatlarında genel mutluluğu yakalama umutlarının yalnızca işyerlerinde mutlu olmaları ile mümkün olabileceğini ifade etmiştir (Gavin ve Mason, 2004: 381). Ancak son ylllarda farklı disiplinleri ortak noktada buluşturan pozitif psikolojinin ilgi odağı olmaya devam eden değişkenlerinden olan meslek aşkı (calling) kavramı Gavin ve Mason'un öne sürdüğü şekliyle yalnızca maddi yeterliliklerin bireylerin mutlulukları yakalamaları konusunda yeterli olamadığı yönünde ilerlemektedir. Örneğin, işte iyi oluş kavramını güçlendirdiği ve işyeri mutluluğu ya da genel mutluluk düzeyini arttırdığı öne sürülen meslek aşkı değişkenini inceleyen ve Duffy ve arkadaşları (2018) tarafından geliştirilen Meslek Aşkı Teorisi (Work as a Calling Theory); bireylerin sadece kazançları doğrultusunda 
yüksek iyi oluş/mutluluk düzeyi elde edemeyeceklerini aynı zamanda sahip oldukları işlerini nasıl algıladıklarının önemli olduğunun altını çizmektedir. Dolayısıyla Wrzesniewski ve arkadaşları (1997) tarafından sahip olunan işlere yaklaşma/algılama biçimlerinden biri olan meslek aşkına sahip olan bireylerin yaptıkları işi yalnızca iş ya da kariyer olarak benimseyenlere nazaran daha mutlu oldukları ifade edilmektedir.

Belirtilen tanımlardan hareketle, işyeri mutluluğu; bireylerin sahip olduğu genel mutluluk düzeylerinden beslenen pozitif duygularını negatif olanlardan daha fazla anımsama durumu ve bu pozitif bakış açısı ile ilişkilendirilen başta umut olmak üzere iyimserlik, şartlardan bağımsız yaşanılan andan keyif alma ve pozitif duygu aktarımı ile kalıcı bir memnuniyet hali şeklinde ifade edilebilir.

Mutlu birey olumsuz duygu halini oldukça nadiren hisseden ancak çoğunlukla olumlu duyguları yaşayan/tecrübe eden birey olarak tanımlanmaktadır (Boehm ve Lyubomirsky, 2008). Sözü edilen olumlu duygular ile hayattan zevk alma, sahip olunan ile mutlu olma, kanaatkarlık/öz memnuniyet, yüksek içsel motivasyon, yaşam ve iş tatmini gibi bireysel ve toplumsal farkl1lık gösterebilen duygu durumlarını ifade edilmektedir. Ancak yaşam döngüsünde sözü edilen mutlu bireylerin iş yaşamlarında da aynı mutluluğu elde edebilecekleri beklentisi ne ölçüde birbirinin devamı olabilecektir sorusu araştırmaların ortaya çıkış nedenlerinin başında yer almaktadır. Genel mutluluk kavramı ya da Uchida ve Kitayama (2009)'nın belirttiği gibi mutsuzluktan kaçınmanın tüm kültürlerin hem fikir olduğu bir konu olduğu ileri sürülmektedir. Dolayısıyla örgütlerin bulundukları toplumun kültürel yapısı ile iç içe olduğu göz önünde bulundurulursa her kültürün mutluluk ya da mutsuzluk durumlarına karşı gösterdikleri tepkiler de farklılaşabilmektedir. Kültürel bağlamda çalışmanın önceki bölümünde örnek olarak verilen Çin'deki 996 iş rejiminin yanı sıra çoğu örgüt daha önceleri çok rastlanmayan "esnek çalışma saatleri" uygulamasını hayata geçirmektedir. Bu uygulamanın sonuçlarını inceleyen bir çalışmada esnek çalışma saatlerinin çalışanların hayat ve iş arasındaki çatışmalarını azalttı̆̆ını ve aynı zamanda çalışanların genel iyi oluş durumlarını da desteklediğini ortaya koymaktadır (Golden vd., 2014). Ancak iş gücünün ucuz olmasına rağmen çalışanların bu ucuz istihdama dahi ihtiyaç duydukları şu dönemde sahip olunan "işin kendisi" bireyleri mutlu 
hissettirebilmektedir. Bu bağlamda çalışanlar hayatta kalabilmek için "iş sahibi olma" duygusu ile mutlu hissedebiliyorken, yalnızca sahip oldukları iş aracılığıyla mutlu hissetmeyen aynı zamanda işini sürdürdüğü ortamdan da çeşitli beklentilere sahip olan çalışanlar mevcuttur. İşyeri mutluluğu kavramı da tam olarak çalışan bireylerin işyerlerinden beklentilerinin ne doğrultuda karşılanması gerektiğinin ve karşılanan beklentiler sonucunda ortaya çıkan olumlu iş çıktılarının önemini vurgulamaktadır.

İşyeri mutluluğu kavramında iş ortamının önemini ortaya koyan çalışmalar ile işyerinde mutluluk ölçekleri geliştirilmiştir (Singh ve Aggarwal, 2018; Salas-Vallina ve Alegre Vidal 2018). Bu ölçeklerde kavramın oluşumunda iş ortamının çalışanlar üzerinde etkisinin mutluluk ile ilişkilendirildiği görülmektedir. Örneğin; destekleyici iş tecrübeleri, desteklenmeyen iş tecrübeleri, akış ve içsel motivasyon, işe antipati hissi şeklinde ifade edilen dört boyutlu yapı hem bireysel hem de örgütsel bazda mutluluğun gelişiminde yöneticilerin çalışanları için hazırladıkları iş çevresi desteğinin önemini vurgulamaktadır (Singh ve Aggarwal, 2018).

\section{b. İşyeri Mutluluğu Kavramının Öncülleri ve Ardılları}

Son yıllarda işyeri mutluluğu kavramı ile ilgili olarak çalışanların işyerlerinde nasıl daha fazla motive olacağı ya da işyerlerine bağlllıklarının nasıl arttırılabileceğine ilişkin öncül ve ardıl değişkenleri içeren modeller kurularak çeşitli araştırmalar yürütülmektedir. Kavramın geliştirilmesi, arttırılması ve sürekliliği örgütler için etkin çalışanlara sahip olma ile sonuçlanması açısından yalnızca teorisyenler için değil aynı zamanda uygulayıcıların da titizlikle ihtiyaç duydukları bir konu haline dönüştürmektedir. Bunun yanı sıra; işyeri mutluluğunun pozitif örgütsel davranış değişkenleri ile ilişkilendirilebileceği ortaya koyulmaktadır (Luthans, 2002). Yakın geçmiş çalışmalarda da işyeri mutluluğu kavramının öncülleri arasında umut, iyimserlik, dayanıklılık, öz yeterlilik gibi içsel psikolojik kaynakların olduğunu modelleyen çalışmalar yapılmıştır (Youssef ve Luthans, 2007; Kun ve Gadanecz, 2019; Qaiser vd., 2020). İşyeri mutluluğu ve öncülleri üzerine yapılan çalışmaların sayılarının artması gerektiğine dikkat çekilmektedir (Erdoğan vd., 2012). 
Erdoğan ve arkadaşları (2012) işyeri mutluluğu kavramını çalışanın liderleri, çalışma ortamı, iş tanımı, iş özelliği, kariyer gelişimi gibi birçok farklı ancak bir o kadar da birbiri ile bağlantısı bulunan değişkenler ile bağdaştırmaktadır. Sözü edilen bu değişkenlerden özellikle çalışanların yöneticileri/liderleri olması bireylerin iş dışı yaşamlarında bulunmayan "yönetici" kavramının iş yaşamının yadsınamaz bir parçası olduğunun da altını çizmektedir. Başta yöneticiler olmak üzere bireyin mutlu yaşantısına yeni eklenen çalışma arkadaşları, müşteriler, çalışma ortamı ve şartları, bireyin mutlu döngüde ilerleyen hayatına bazı dolaylı ya da dolaysız etkiler meydana getirecektir. Bu bağlamda iş yeri mutluluğu bireyin kısa bir sürede temel mutluluğu ile iç içe geçebilecektir. Bu durumda yoğun çalışma saatleri, iş yeri ortamı, ücret, yönetici tutumu gibi çeşitli kavramlar çalışanlar tarafından farklı algılanabilecektir. Bu farklılıklar göz önünde bulundurularak bağımlı bağımsız değişkenlerin yanı sıra işyeri mutluluğu ile yapılan çalışmalarda bazı demografik değişkenlerde özellikle ele alınmıştır. Çalışan davranışını şekillendirmede önemli bir yere sahip olduğu ileri sürülen işyeri mutluluğunun (De Neve ve Ward, 2017) örgütsel vatandaşlığın yordayıcısı olarak kullanıldığı bir çalışmada Mousa ve arkadaşları (2020) cinsiyetin işyeri mutluluğu üzerinde bir etkisinin olmadığını ortaya koymuştur. Cinsiyet değişkeni ile birlikte Ongkana (2006) yaş, medeni durum ve kıdemin de işyeri mutluluğunun üzerinde bir etkisinin olmadığını ortaya koymuştur. İşyeri mutluluğu ile ilgili alanyazın incelendiğinde işyeri mutluluğunun öncülleri Tablo 1'de gösterilmiştir.

Tablo 1. İşyeri Mutluluğu Kavramının Öncülleri

\begin{tabular}{|c|c|c|}
\hline Öncüller & Çalışma & Açıklama \\
\hline Şükür & Kir vd. (2020) & Şükür düzeyi arttıkça işyeri mutluluğu artmaktadır. \\
\hline $\begin{array}{l}\text { İnsan Kaynakları } \\
\text { Yönetimi } \\
\text { Politikaları } \\
\text { Alg1sı, Örgütsel } \\
\text { Güven }\end{array}$ & Oliveira vd. (2020) & $\begin{array}{l}\text { Çalışanın örgüte olan güveni arttıkça işyeri } \\
\text { mutluluğu artmaktadır. İnsan Kaynakları Yönetimi } \\
\text { Politikaları Algısı ile çalışanların olumlu } \\
\text { duygularını açığa çıarma desteği arttıkça işyeri } \\
\text { mutluluğu artmaktadır. }\end{array}$ \\
\hline $\begin{array}{l}\text { Yüksek } \\
\text { Performanslı İş } \\
\text { Sistemi }\end{array}$ & Fatima vd. (2017) & $\begin{array}{l}\text { Yüksek Performanslı İş Sistemi algısı arttıkça işyeri } \\
\text { mutluluğu artmaktadır. }\end{array}$ \\
\hline $\begin{array}{l}\text { Algilanan } \\
\text { Örgütsel Destek, } \\
\text { Psikolojik } \\
\text { Sermaye }\end{array}$ & Joo ve Lee (2017) & $\begin{array}{l}\text { Algılanan Örgütsel Destek ve Psikolojik Sermaye } \\
\text { algısı arttıkça işyeri mutluluğu artmaktadır. }\end{array}$ \\
\hline
\end{tabular}




\begin{tabular}{|c|c|c|}
\hline $\begin{array}{l}\text { Psikolojik } \\
\text { sözleşme ihlali }\end{array}$ & Qaiser vd. (2020) & $\begin{array}{l}\text { Psikolojik Sözleşme İhlali algısı arttıkça işyeri } \\
\text { mutluluğu azalmaktadır. }\end{array}$ \\
\hline $\begin{array}{l}\text { İş'te Kendini } \\
\text { Yetiştime }\end{array}$ & Qaiser vd. (2020) & $\begin{array}{l}\text { İş'te Kendini Yetiştirme arttıkça işyeri mutluluğu } \\
\text { artmaktadır. }\end{array}$ \\
\hline $\begin{array}{l}\text { Kişi - Örgüt } \\
\text { Uyumu }\end{array}$ & Sousa ve Porto (2015) & $\begin{array}{l}\text { Kişi-Örgüt uyumu arttıkça işyeri mutluluğu } \\
\text { artmaktadır. }\end{array}$ \\
\hline Özgeci Liderlik & $\begin{array}{l}\text { Salas-Vallina ve Alegre } \\
(2018)\end{array}$ & $\begin{array}{l}\text { Özgeci Liderlik davranışı arttıkça işyeri mutluluğu } \\
\text { artmaktadır. }\end{array}$ \\
\hline İş Tatmini & Butt vd. (2020) & İş Tatmini arttıkça işyeri mutluluğu artmaktadır. \\
\hline Duygusal Zekâ & Karayaman (2020) & $\begin{array}{l}\text { Duygusal Zekâ düzeyi arttıkça işyeri mutluluğu da } \\
\text { artmaktadır. }\end{array}$ \\
\hline $\begin{array}{l}\text { Psikolojik } \\
\text { Güçlendirme }\end{array}$ & $\begin{array}{l}\text { Özocak ve Yilmaz } \\
(2020)\end{array}$ & $\begin{array}{l}\text { Psikolojik Güçlendirme düzeyi arttıkça işyeri } \\
\text { mutluluğu artmaktadır. }\end{array}$ \\
\hline $\begin{array}{l}\text { Transformasyone } \\
1 \text { Liderlik }\end{array}$ & Salas-Vallina vd. (2017) & $\begin{array}{l}\text { Transformasyonel Liderlik davranışı arttıkça işyeri } \\
\text { mutluluğu artmaktadır. }\end{array}$ \\
\hline İşin anlamı & $\begin{array}{l}\text { Golparvar ve Abedini } \\
(2014)\end{array}$ & İşin anlamı arttıkça işyeri mutluluğu artmaktadır. \\
\hline İşyeri ruhsallı̆̆g & $\begin{array}{l}\text { Golparvar ve Abedini } \\
(2014)\end{array}$ & $\begin{array}{l}\text { İşyeri ruhsallığı arttıkça işyeri mutluluğu } \\
\text { artmaktadır. }\end{array}$ \\
\hline $\begin{array}{l}\text { Sosyal Sermaye, } \\
\text { Psikolojik } \\
\text { Sermaye }\end{array}$ & Taştan vd. (2020) & $\begin{array}{l}\text { Sosyal ve Psikolojik Sermaye arttıkça işyeri } \\
\text { mutluluğu artmaktadır. }\end{array}$ \\
\hline $\begin{array}{l}\text { Psikolojik } \\
\text { Sağlamlık }\end{array}$ & Ali vd. (2019) & $\begin{array}{l}\text { Psikolojik Sağlamlık arttıkça işyeri mutluluğu } \\
\text { artmaktadır. }\end{array}$ \\
\hline Örgütsel Adalet & Maham vd. (2020) & $\begin{array}{l}\text { Örgütsel Adalet algısı arttıkça işyeri mutluluğu } \\
\text { artmaktadır. }\end{array}$ \\
\hline
\end{tabular}

İşyeri mutluluğu kavramını tanımlarken iki taraflı bir beklenti durumu olduğunu söylemek mümkündür. Bir tarafta takdir edilmeyi, fark edilmeyi, saygı duyulmayı, değer verilmeyi, mutlu olmayı beklentilerinin en başına koyan çalışanlar ile diğer yanda işini kendi işiymiş gibi benimseyen, örgütü sürekli rekabetin içinde tutacak yeterliliğe sahip olan çalışanların varlığının beklentisi içerisinde olan işverenler bulunmaktadır (Oliveira, 2020). Çalışanlar işyerinde mutlu oldukları zaman bu durum olumlu iş sonuçlarının düzeyini arttırmakta ve olumsuz iş çıktılarının düzeyini azaltmaktadır. İşyeri mutluluğu ile ilgili alanyazın incelendiğinde işyeri mutluluğunun ardılları Tablo 2' de gösterilmiştir. 
Tablo 2. İşyeri Mutluluğu Kavramının Ardılları

\begin{tabular}{|c|c|c|}
\hline Ardıllar & Çalışma & Açıklama \\
\hline Yenilikçi İş Davranışı & Uzunbacak (2019) & $\begin{array}{l}\text { İşyeri mutluluğu arttıkça yenilikçi iş } \\
\text { davranışı artmaktadır. }\end{array}$ \\
\hline Örgütsel Performans & Fatima vd. (2017) & $\begin{array}{l}\text { İşyeri mutluluğu arttıkça örgütsel } \\
\text { performans artmaktadır. }\end{array}$ \\
\hline $\begin{array}{l}\text { Fazladan } \\
\text { Davranışı }\end{array}$ & Alparslan (2016) & $\begin{array}{l}\text { İşyeri mutluluğu arttıkça fazladan rol } \\
\text { davranışı artmaktadır. }\end{array}$ \\
\hline $\begin{array}{l}\text { Örgütsel Vatandaşlık } \\
\text { Davranışı }\end{array}$ & Mousa vd. (2020) & $\begin{array}{l}\text { İşyeri mutluluğu arttıkça örgütsel } \\
\text { vatandaşlık davranışı artmaktadır. }\end{array}$ \\
\hline Çalışan Performansı & Bataineh (2019) & $\begin{array}{l}\text { İşyeri mutluluğu arttıkça çalışan } \\
\text { performansı artmaktadır. }\end{array}$ \\
\hline İşten Ayrılma Niyeti & Wang ve Yang (2016) & $\begin{array}{l}\text { İşyeri mutluluğu arttıkça işten ayrılma niyeti } \\
\text { azalmaktadır. }\end{array}$ \\
\hline Örgütsel Bağlilık & Uzun ve Kesicioğlu (2019) & $\begin{array}{l}\text { İşyeri mutluluğu arttıkça örgütsel bağlılık } \\
\text { artmaktadır. }\end{array}$ \\
\hline İşe Adanmışlık & Kim (2019) & $\begin{array}{l}\text { İşyeri mutluluğu arttıkça işe adanmışlık } \\
\text { artmaktadır. }\end{array}$ \\
\hline İş Tatmini & $\begin{array}{l}\text { Thevanes ve Jathurika } \\
\text { (2021); Butt vd. (2019) }\end{array}$ & $\begin{array}{l}\text { İşyeri mutluluğu arttıkça iş tatmini } \\
\text { artmaktadır. }\end{array}$ \\
\hline Psikolojik İyi Oluş & $\begin{array}{l}\text { Golparvar ve Abedini } \\
(2014)\end{array}$ & $\begin{array}{l}\text { İşyeri mutluluğu arttıkça psikolojik iyi oluş } \\
\text { artmaktadır. }\end{array}$ \\
\hline Duygusal Bağlılık & Semedo vd. (2019) & $\begin{array}{l}\text { İşyeri mutluluğu arttıkça duygusal bağlılık } \\
\text { artmaktadır. }\end{array}$ \\
\hline
\end{tabular}

\section{Sonuç}

Yerel ve küresel rekabetler gerek üretim gerekse hizmet üreten örgütleri mecburi dönüşümler ya da yenilikler ortaya çıkarmaları doğrultusunda yönlendirmektedir. Örgütler bu değişimleri sahip oldukları iş gücü yeterliliğine bağlı olarak geliştirmekte ve sürdürebilmektedir. Bu bağlamda iş gücünü oluşturan örgüt çalışanlarının hangi mutluluk ve motivasyon kaynaklarından beslendiklerini belirlemek örgütlerin önceliği haline gelmektedir. Nitelikli iş gücü, çalışanların istihdam kaygısı doğrultusunda şekillenmekte ve her geçen gün alanında uzman bireyler yeniliğe uyum sağlayan, teknolojik gelişmeleri yakından takip eden bireyler kurumsal örgütlerde yerlerini almaya devam etmektedir. Ancak, belirtilen bu somut gelişmelerin yanı sıra, örgütün iş gücü potansiyelini oluşturan örgüt çalışanlarının duygu durumları da incelenmeye devam edilmektedir. 
İşyeri mutluluğu kavramının gelişmiş batı toplumlarında gelişmekte olan toplumlara göre daha fazla araştırıldığı (Chin, 2015) ileri sürülürken; kurumsal örgütlerin sürdürülebilirlik bilincine sahip olması da işyeri mutluluğunun üst düzey yöneticiler tarafından benimsenmesi gerektiğinin altını çizmektedir. Sözü edilen sürdürülebilirlik farkındalığ 1 örgütlerin itibar, takdir görme, çalışanına değer verme gibi görünmeyen değerlere de maddi kaynaklar ayırmasını gerektirecektir. Dolayısıyla, özellikle gelişmiş batı toplumlarında çalışanların belirli bir yaşam doyumuna ulaşması ve iş dışı refah seviyesini işinde de elde etme beklentisi işverenleri daha fazla davranışsal değişkenleri anlamaya yönlendirmektedir.

Özellikle son yıllarda pozitif örgütsel davranış değişkenlerinin başında yer alan işyeri mutluluğu kavramının birçok olumlu iş çıktısına neden olması örgütlerin gelişiminde önemli rol oynamaktadır. Dolayısıyla biyolojik açıdan benzer ihtiyaçlara sahip olan insanoğlu mutluluk söz konusu olduğunda farklı kaynaklar aracılığıyla bu nihai tatmini yaşamaktadır. Öyle ki para ile mutluluk kıyaslamalarında çoğunlukla daha fazla paranın mutluluk getireceğini ileri sürenler para ile mutluluk arasındaki ilişkinin düşük olduğunun altını çizmektedir (Adams vd., 2002). Ancak çalışmanın kavramsal çerçevesinde belirtilen nüfus yoğunluğunun yüksek ve refah seviyesinin düşük olduğu toplumlar gelişmiş ve varlıklı toplumlara göre maddi öncelikleri konusunda farklılık göstermektedir. Hayatta kalma mücadelesi anlam arayışı, kendine ve topluma fayda sağlama, kişisel gelişim gibi kavramların önünde yer almaya başlamıştır. Bununla birlikte son yıllarda ortaya çıkan ve teorisyenler arasında hızla yayılan meslek aşkı (calling), anlam (meaning) ve çalışma iradesi/istemi (work volition) gibi kavramlarda çalışan motivasyonunun soyut yönünü incelemektedir. Bu kavramlar ile özellikle çalışanların sahip oldukları işlerden yalnızca maddi kazanç değil onlara kendilerini değerli hissettiren manevi tatminler aradıkları da ileri sürülmektedir (Dik vd., 2020).

Çalışan bireyler zamanlarının büyük bir çoğunluğunu iş yerinde geçirmektedir. Dolayısıyla, bu uzun zaman dilimini mutlu, motivasyonu yüksek, saygı ve değer görerek tamamlamak istemeleri örgüt çalışanlarının öncelikli beklentilerindendir. İnsanlar sahip oldukları işlerden ne kadar mutlu oldukları beklentileri doğrultusunda çeşitlilik 
gösterebilmektedir. Bununla birlikte, bireylerin gerçek potansiyellerini ortaya koyma konusunda da işyerindeki duygu durumlarının rolü önemli bir yer teşkil etmektedir. Son yıllarda yaşanan ekonomik dalgalanmaların etkisiyle küresel bazda ortaya çıkan işsizlik etkileri devam ederken, diğer taraftan nitelikli iş gücünün de örgütlerde devamlılığını sağlamak zorlaşmaktadır. Nitelikli iş gücü kişisel gelişim ya da mesleki gelişim yönünden sağlayamadığı tatmini örgütten ayrılma veya potansiyelinin altında performans göstermeye başlayabilmektedir. Ancak, nitelikli iş gücü kaybı örgütler için başa çıkılabilir bir süreç gibi görünse de zaman ve maddi kaynak kaybına yol açabilmektedir. Hem örgütsel davranış hem de pozitif psikoloji disiplinlerinde son yıllarda en çok incelenen kavramlar arasında iş yeri mutluluğunun öncülleri veya ardılları olarak bağlılık, adanmışlık, mutluluk, motivasyon, performans, tatmin gibi psikolojik kavramlar yer almaktadır.

Çalışanların hangi psikolojik değişkeni tecrübe ettiklerinde hangi sonuçlar ortaya çıkacağına dair araştırmaların sayısı her geçen gün artmaktadır. $\mathrm{Bu}$ artış akademisyenler ve uygulayıcılar için çalışan davranışlarının altında yer alan sebepleri anlama konusunda yeni alanlar oluşturmaktadır. Bu çalışmada kavramsal açıdan değerlendirilen "iş yeri mutluluğu" da bunlardan bir tanesidir. Bireylerin iş yerlerinde geçirdikleri zamanın iş çevresi dışında geçirdikleri zamandan fazla olduğu göz önünde bulundurulduğunda bu mutluluğun elde edilmesi yalnızca bireylerin maddi kazançları, mevki hedefleri ile doğrudan ilişkilendirilmemektedir. Bir başka deyişle materyalist hedefler gerekli ancak mutlu olmanın ön şartı olarak yeterli olmamaktadır (Fischer, 2014). Örgütler işyerinde mutlu çalışanlara sahip oldukları takdirde bu mutlu çalışanların daha iyi fiziksel ve psikolojik olarak daha sağlıklı ve aynı zamanda daha uzun ömürlü oldukları ifade edilmektedir (Røysamb vd., 2003). Dolayısıyla örgütler eş zamanlı sağlıklı çalışanlara sahip olmanın avantajını da uzun vadede özel sağlık harcamasına gerek duymadan elde edebileceklerdir. Öte yandan, eğitim kurumları özellikle üniversiteler öğrencilerini yalnızca gelecekteki mesleklerine hazırlamak ve onlara meslekleri konusunda eğitim vermenin yanı sıra öğrencilerinin sahip olduğu potansiyellerine yönelik farkındalıklarını ve bireysel yaşamlarında da mutluluklarını arttırmak doğrultusunda yönlendirmeler yapmalıdır (Bok, 2010). Erken dönemde başlayan bu katkı ve 
yönlendirmeler bireylerin gelecek iş hayatlarında da mutlu bireyler olmalarının avantajlarını yaşamalarını sağlayacak ve işyerlerinde karşılaştıkları engeller karşısında olumlu duygu durumları ile bu engeller ile baş etmeleri kolaylaşabilecektir. Ayrıca son yıllarda özellikle pozitif psikolojinin önemli araştırma konularından birisi olan meslek aşkı(calling) kavramının da işyeri mutluluğu kavramı ile daha ayrıntılı araştırmalar ile incelenmesi gerektiği düşünülmektedir. Çünkü bireyler yalnızca işyeri ortamının ya da kendi kişilik özelliklerinin etkisi altında kendilerini işyerinde mutlu hissetmemektedir aynı zamanda bireylerin işlerine duydukları bağlanma yaklaşımı da işyerinde mutlu olmalarında rol oynamaktadır. Alan yazın incelendiğinde bireyler sahip oldukları iş ne olursa olsun işin kendisine karşı hissettikleri meslek aşkı (calling) algısı bireyleri iş yeri şartlarından ve çalışma saatlerinden bağımsız olarak mutlu hissettirebilmektedir (Bunderson ve Thompson, 2009). Bununla birlikte, gelişmiş ve gelişmekte olan ülkelerin, bireylerin sahip oldukları işlere karşı ortaya koydukları tutumlarında incelenmesi söz konusu olabilir. Her toplumun üst düzey alg1 ve yeterlilik gerektiren işlerin ortaya konulabilmesi için ihtiyaç duyduğu belirli bir iş gücü potansiyeli olmakla birlikte aynı toplumun daha alt düzey, yapılması güç farklı iş kollarını da yerine getirecek iş gücüne ihtiyacı da olmaktadır. Dolayısıyla, hep toplumun bakış açısının hem de bireylerin sahip oldukları işlere karşı tutumlarının işyeri mutluluğu konusunda önem teşkil ettiği düşünülmektedir. 


\title{
EXTENDED ABSTRACT
}

\section{Workplace Happiness: A Concept Analysis}

\author{
Tuğba Erhan \\ Süleyman Demirel University
}

The concept of happiness has been gaining attention among the positive psychology variables which supports the strengths of individuals rather than their weaknesses. In the discipline of positive psychology, organizational behavior and management, the term happiness has been examining for a long time. Happiness can be stated as the final destination as a result of the individuals' behaviors, efforts and hard work. Individuals may pursue several different goals during their lives. However, individuals may have several goals, which is based on the Goal Setting Theory (Locke and Latham, 1990), that they need to pursue at the same time, and they have the tendency to believe that when the goals are accomplished, they will have the chance to be happy. Happiness which includes the individuals' cognitive and affective evaluations (Diener, 2000), has been used with subjective well-being interchangeably (Luthans, 2002; Diener, 2000). The term "subjective" highlights that the happiness changes from individual to individual, and as Aristotle states happiness is a virtue (Myers and Diener, 1995).

\section{Theoretical Background of Workplace Happiness}

Happy individuals have been defined as individuals who experience more positive feelings (Boehm and Lyubomirsky, 2008). According to Haller and Hadler (2006, pp.172-174); the term "happiness" has been explained with the following five theoretical approaches;

- Individuals' unchanged characteristics

- A consequence of living an objective life

- A source which is beneficial for individuals

- Subjective satisfaction process compared to other individuals

- Permanent national or cultural qualification 
In addition to the aforementioned theories of happiness, a study which has claimed that happiness is related to job performance and the difference being a happy and an unhappy employee has reflections on workplace environment (Cropanzano and Wright, 2001). The study also reveals the psychological situations of the happy and unhappy employees highlighting the outcomes of unhappy employees. According to the study, unhappy employees are more sensitive to the workplace risks, more defensive to their colleagues and cautious, less optimistic, and less selfconfident. However, happy employees are more sensitive to the opportunities in the workplace or work environment, more extroverted and sociable with their colleagues, more helpful and more self-confident Cropanzano and Wright, 2001, pp.183-184).

\section{Antecedents and Consequences of Workplace Happiness}

The studies conducted to examine the antecedents and consequences of workplace happiness have been attempting to find sources to make the employees happier and more committed in the workplace. Gratitude (Kir et al., 2020); people management policies and trust Oliveira et al. (2020); high performance work practices (Fatima et al., 2017); perceived organizational support and psychological capital (Joo and Lee, 2017); psychological contract breach (Qaiser et al., 2020); thriving at work (Qaiser et al., 2020); person-organization fit (Sousa and Porto, 2015); altruistic leadership (Salas-Vallina and Alegre, 2018); job satisfaction Butt et al., 2020); emotional intelligence (Karayaman, 2020); psychological empowerment (Özocak and Yılmaz, 2020); transformational leadership (Salas-Vallina et al., 2017); meaning at work (Golparvar and Abedini, 2014); spiritual-affective approach (Golparvar and Abedini, 2014); social and psychological capital (Taştan et al., 2020); psychological resilience (Ali et al., 2019); organizational justice (Maham et al., 2020) are among the antecedents of workplace happiness. When the consequences of workplace happiness have been examined innovative work (Uzunbacak, 2019); organizational performance (Fatima et. al., 2017); extra-role behavior (Alparslan, 2016); organizational citizenship (Mousa et al., 2020); employee performance (Bataineh, 2019); turnover intention (Wang and Yang, 2016); organizational commitment (Uzun and Kesicioğlu, 2019); 
work engagement (Kim, 2019); job satisfaction (Thevanes and Jathurika, 2021; Butt et al., 2019); psychological well-being (Golpalvar and Abedini, 2014); affective commitment (Semedo et al., 2019) are among the outcome variables that workplace happiness affect.

\section{Conclusion}

Local and global competitions have been leading product and service organizations to apply innovations or transformations to be a part of the challenging competitive process. Organizations have been improving and following these changes with the support of the workforce. In order to become a strong competitor among the other organizations, the workforce should be analyzed identifying their happiness and motivational sources that the workforce has been experiencing. The workplace is an environment that employees spend their most of the time. Thus, the employees' psychological needs matter on the effect of the productivity of the organization. Well qualified workforce has been shaping along with the employment expectations, thus employees who want to work in the most appreciated organizations should improve their skills as well as their approaches to the new technology. However, in addition to the developments which arise the potentiality of the employees also bring out another aspect of the employees which is their emotional states.

It is claimed that the term workplace happiness has been researched more in the western societies compared to developing societies (Chin, 2015). Organizations need to hire managers who agree the importance of happy employees fully support to fulfill the organizational goals and sustainability. By being aware of the importance of sustainability, organizations invest for the invisible values such as reputation, appreciation, and value their employees. Therefore, especially the expectations of being fully satisfied and happy in the workplace can be made possible by examining the behavioral variables.

The fact that the concept of workplace happiness, which has been one of the important positive psychology variables specifically in recent years, has been causing many positive work outcomes that these outcomes can play an important role in the development of the organizations. Thus, it should be considered that although individuals share the same biological 
needs, they completely differ in their happiness sources to feel fully satisfied both in their work and lives. When the studies between happiness and money have been examined, the relationship and the correlation have been reported low (Adams et al., 2002). However, as it has been stated in the theoretical part of the current study, countries with high population and low welfare may differ in their financial priorities. Survival can be the main priority rather than prosocial benefits or personal growth improving the meaning of work or life.

In addition to this, terms like calling, meaning and work volition have been spreading to be researched recently in order to reveal and examine the employee motivation. It has been stated that these terms especially the term "calling" highlights an important outcome for the employees emphasizing that the employees are not just satisfied with the paycheck but internal motivators including spiritual satisfaction (Dik et al., 2020).

\section{Kaynakça / References}

Abraham, S. (2015). Factors influencing workplace happiness among employees in software companies in Bangalore. International Journal of Research in Applied Management Science and Technology, II (I).

Adams VH, Snyder CR, Rand KL, King EA, Sigman DR, Pulvers KM. (2002). Hope in the workplace içinde Giacolone R, Jurkiewicz C. (Eds.), Workplace spirituality and organization performance. New York: Sharpe.

Adnan Bataineh, K. (2019). Impact of work-life balance, happiness at work, on employee performance. International Business Research, 12(2), 99-112.

Ali, M., Ghani, M. U., and Raza, B. (2019). Linking human resource practice with work happiness through employee resilience: Evidence from Pakistan. Global Regional Review, 4(3), 82-91.

Alparslan, A. M. (2016). Emek işçilerinde fazladan rol davranışının öncülü: iş tatmini mi işyerinde mutluluk mu?. Atatürk Üniversitesi İktisadi ve İdari Bilimler Dergisi, 30(1), 203-215.

Bani-Melhem, S., Zeffane, R. ve Albaity, M. (2018). Determinants of employees' innovative behavior. International Journal of Contemporary Hospitality Management, 30 (3), 1601- 1620. 
Boehm, J. K. ve Lyubomirsky, S. (2008). Does happiness promote career success? Journal of Career Assessment, 16(1), 101-116.

Bok, D. (2010). The politics of happiness: What government can learn from the new research on well-being. Princeton University Press.

Bunderson, J. S. ve Thompson, J. A. (2009). The call of the wild: Zookeepers, callings, and the double-edged sword of deeply meaningful work. Administrative science quarterly, 54(1), 32-57.

Butt, R. S., Altaf, S., Chohan, I. M. ve Ashraf, S. F. (2019). Analyzing the role of quality of work life and happiness at work on employees' job satisfaction with the moderation of job stress, empirical research of Jiangsu University. International Journal of Scientific and Technology Research, 8(10), 1905-1915.

Butt, R. S., Wen, X. ve Hussain, R. Y. (2020). Mediated effect of employee job satisfaction on employees' happiness at work and analysis of motivational factors: evidence from telecommunication sector. Asian Business Research Journal, 5, 19-27.

Chin, T. (2015). Harmony and organizational citizenship behavior in Chinese organizations. The International Journal of Human Resource Management, 26(8), 1110-1129.

Chiumento, S. (2007). Happiness at work index: Research report 2007. London: Chiumento

Cropanzano, R. ve Wright, T. A. (2001). When a" happy" worker is really a" productive" worker: A review and further refinement of the happyproductive worker thesis. Consulting Psychology Journal: Practice and Research, 53(3), 182.

De Neve, J. E. ve Ward, G. (2017). Happiness at work. Saïd Business School $W P, 7,1-78$.

de Waal, A. (2018). Increasing organisational attractiveness: the role of the HPO and happiness at work frameworks. Journal of Organizational Effectiveness: People and Performance, 5(2), 124- 141.

Demir, R. ve Türk, F. (2020). Pozitif psikoloji: Tarihçe, temel kavramlar, terapötik süreç, eleştiriler ve katkılar. Humanistic Perspective, 2(2), 108125.

Diener, E. (2000). Subjective well-being: The science of happiness and a proposal for a national index. American psychologist, 55(1), 34- 43. 
Dik, B. J., Steger, M. F., ve Autin, K. L. (2020). Emerging Perspectives: Calling, Meaning, and Volition içinde Brown S.D., Lent R. W. (Eds.), Career Development and Counseling: Putting Theory and Research to Work, 237270.

Duffy, R. D., Dik, B. J., Douglass, R. P., England, J. W., ve Velez, B. L. (2018). Work as a calling: A theoretical model. Journal of Counseling Psychology, 65(4), 423- 439.

Edmunds, L. D. ve Pryce-Jones, J. (2008). Relationships between happiness, overtime, sick leave and intention to stay or leave. Selection and Development Review, 24(1), 812.

Erdogan, B., Bauer, T. N., Truxillo, D. M., ve Mansfield, L. R. (2012). Whistle while you work: A review of the life satisfaction literature. Journal of Management, 38(4), 1038-1083.

Fatima, A., Imran, R. ve Noreen, U. Antecedents and outcomes of employee wellbeing: A path model approach, Journal of Innovative Research in Education and Management, 1(1), 40-50.

Fischer, E. F. (2014). The good life: Aspiration, dignity, and the anthropology of wellbeing. Stanford University Press.

Fredrickson, B. L. (1998). What good are positive emotions? Review of General Psychology, 2(3), 300-319.

Fredrickson, B. L. (2001). The role of positive emotions in positive psychology: The broaden-and-build theory of positive emotions. American Psychologist, 56(3), 218- 226.

Fredrickson, B. L. (2003). Positive emotions and upward spirals in organizational settings içinde K. S. Cameron, J. E. Dutton, R. E. Quinn, (Eds.) Positive organizational scholarship: Foundations of a new discipline. San Francisco: Berrett Koehler. 163-175.

Gavin, J. H., ve Mason, R. O. (2004). The Virtuous Organization: The value of happiness in the workplace. Organizational Dynamics, 33(4), 379-392.

Golden, L., Henly, J. ve Lambert, S. (2013). Work schedule flexibility: a contributor to employee happiness? Journal of Social Research and Policy, 4 (2), 107-135.

Golparvar, M., and Abedini, H. (2014). The relationship between spirituality and meaning at work and the job happiness and psychological wellbeing: A spiritual-affective approach to the psychological wellbeing. International Journal of Management and Sustainability, 3(3), 160175. 
Gregory, K. (2011). The importance of employee satisfaction. The Journal of the Division of Business and Information Management, 5, 29-37.

Haller, M. ve Hadler, M. (2006). How social relations and structures can produce happiness and unhappiness: An international comparative analysis. Social Indicators Research, 75(2), 169-216.

Haybron, D. M. (2013). The nature and significance of happiness. The Oxford Handbook of Happiness, 303-314.

Joo, B. K. ve Lee, I. (2017). Workplace happiness: Work engagement, career satisfaction, and subjective well-being içinde Evidence-based HRM: A Global Forum for Empirical Scholarship. Emerald Publishing Limited. 5(2), 206- 221.

Judge, T. A., Bono, J. E., Thoresen, C. J. ve Patton, G. K. (2001). The job satisfaction-job performance relationship: A qualitative and quantitative review. Psychological Bulletin, 127, 376-407.

Karayaman, S. (2020). Yönetimde Duygusal Zekâ ve İşyeri Mutluluğu İlişkisi: Okul Yöneticileri Örneği. İstanbul Gelişim Üniversitesi Sosyal Bilimler Dergisi, 8(1), 51-66.

Kim, K. S. (2019). The influence of hotels high commitment hrm on job engagement of employees: Mediating effects of workplace happiness and mental health. Applied Research in Quality of Life, 14(2), 507-525.

Kır, A., Kösem, Ü., Akçakanat, T., ve Uzunbacak, H. H. (2020). Öğretmenlerde şükrün işyeri mutluluğuna etkisinde cinsiyetin düzenleyici rolü. Uluslararasi İktisadi ve İdari Bilimler Dergisi, 6(2), 5-18.

Köroğlu, S. A. (2015). Literatür taramasi üzerine notlar ve bir tarama tekniği. GiDB Dergi, (01), 61-69.

Kun, A. ve Gadanecz, P. (2019). Workplace happiness, well-being and their relationship with psychological capital: A study of Hungarian Teachers. Current Psychology, 1-15.

Locke, E. A. ve Latham, G. P. (1990). A theory of goal setting and task performance. Englewood Cliffs, NJ: Prentice-Hall

Luthans, F. (2002). Positive organizational behavior: Developing and managing psychological strengths. Academy of Management Perspectives, 16(1), 57-72.

Luthans, F. (2002). The need for and meaning of positive organizational behavior. Journal of Organizational Behaviour, 23, 695-706. 
Lyubomirsky, S., ve Layous, K. (2013). How do simple positive activities increase well-being?. Current Directions in Psychological Science, 22(1), 57-62.

Maham, R., Bhatti, O. K., ve Öztürk, A. O. (2020). Impact of Islamic spirituality and Islamic social responsibility on employee happiness with perceived organizational justice as a mediator. Cogent Business an Management, 7(1), 1- 20.

Maslow, A. H. (1943). A theory of human motivation. Psychological Review, 50(4), 370-396.

Mousa, M., Massoud, H. K. ve Ayoubi, R. M. (2020). Gender, diversity management perceptions, workplace happiness and organisational citizenship behaviour. Employee Relations: The International Journal, 42(6), 1246- 1269.

Myers, D. G. ve Diener, E. (1995). Who is happy?. Psychological Science, 6(1), 10-19.

Oliveira, A. F., Gomide Júnior, S. ve Poli, B. V. S. (2020). Antecedents of wellbeing at work: trust and people management policies. RAM. Revista de Administração Mackenzie, 21(1), 1- 26.

Ongkana, K. (2006). Relationships between personal factors, self-esteem, work environment, and joy at work of staff nurses, private hospitals, Bangkok metropolis. (Unpublished Master Thesis). Chulalongkorn University.

Özocak, A., ve Yılmaz, E. (2020). Öğretmenlerin psikolojik güçlendirilmelerinin örgütsel mutluluklarına etkisi. Çă̆daş Yönetim Bilimleri Dergisi, 7(1), 80-94.

Peterson, C., Park, N., and Seligman, M. E. (2005). Orientations to happiness and life satisfaction: The full life versus the empty life. Journal of Happiness Studies, 6(1), 25-41.

Qaiser, S., Abid, G., Arya, B., ve Farooqi, S. (2020). Nourishing the bliss: Antecedents and mechanism of happiness at work. Total Quality Management and Business Excellence, 31(15-16), 1669-1683.

Quick, J. C. ve Quick, J. D. (2004). Health, happy, productive work: A leadership challenge. Organizational Dynamics, 33(4), 329-337. 
Røysamb, E., Tambs, K., Reichborn-Kjennerud, T., Neale, M. C., ve Harris, J. R. (2003). Happiness and health: environmental and genetic contributions to the relationship between subjective well-being, perceived health, and somatic illness. Journal of Personality and Social Psychology, 85(6), 1136- 1146.

Salas-Vallina, A. ve Alegre, J. (2018). Happiness at work: Developing a shorter measure. Journal of Management and Organization, 1, 21. DOI: 10.1017/jmo.2018.24

Salas-Vallina, A. ve Alegre, J. (2018). Unselfish leaders? Understanding the role of altruistic leadership and organizational learning on happiness at work (HAW). Leadership and Organization Development Journal. 39(5), 633-649.

Salas-Vallina, A., López-Cabrales, Á., Alegre, J. and Fernández, R. (2017), "On the road to happiness at work (HAW): Transformational leadership and organizational learning capability as drivers of HAW in a healthcare context", Personnel Review, 46(2), pp. 314-338.

Seligman, M. E. (2011). Flourish: A visionary new understanding of happiness and well-being (1st Free Press hardcover ed.). New York, NY: Free Press.

Semedo, A. S., Coelho, A., and Ribeiro, N. (2019). Authentic leadership, happiness at work and affective commitment. European Business Review. 31(3), 337-351.

Simmons, B. L. (2014). Organizational characteristics of happy organizations. Wellbeing: A Complete Reference Guide, 1-18.

Singh, S. ve Aggarwal, Y. (2018). Happiness at work scale: construction and psychometric validation of a measure using mixed method approach. Journal of Happiness Studies, 19(5), 1439-1463.

Sousa, J. M. D., ve Porto, J. B. (2015). Happiness at work: organizational values and person-organization fit impact. Paidéia (Ribeirão Preto), 25(61), 211-220.

Stairs, M. ve Galpin, M. (2010). Positive engagement: From employee engagement to workplace happiness içinde P. A. Linley, S. Harrington ve N. Garcea (Eds.), Oxford Library of Psychology. Oxford Handbook of Positive Psychology and Work (155-172). Oxford University Press.

Suikkanen, J. (2011). An improved whole life satisfaction theory of happiness. International Journal of Wellbeing, 1(1), 149- 166.

Sumner, W. (1996). Welfare, happiness, and ethics. Oxford: Clarendon Press. 
Suojanen, I. (2012). Work for your Happiness, defining and measuring happiness at work. Unpublished master's thesis, University of Turku, Turun.

Taştan, S., Küçük, B. A., ve Işiaçik, S. (2020). Towards enhancing happiness at work with the lenses of positive organizational behavior: The roles of psychological capital, social capital and organizational trust. Postmodern Openings/Deschideri Postmoderne, 11(2), 192-225.

Thevanes, N., and Jathurika, M. (2021) Employee happiness and its relationship with job satisfaction: An empirical study of academic staff in a selected Sri Lankan University. Asian Journal of Social Science and Management Technology, 3(1), 34-43.

Uchida, Y. ve Kitayama, S. (2009). Happiness and unhappiness in east and west: Themes and variations. Emotion, 9(4), 441- 456.

Uzun, T. ve Kesicioglu, O. S. (2019). Okul öncesi öğretmenlerinin örgütsel mutluluğu ile iş tatminleri ve örgütsel bağlılıkları arasındaki iliskilerin incelenmesi. Akdeniz Eğitim Araştırmaları Dergisi, 13(29), 3952.

Uzunbacak, H.H. (2019), The moderating role of coworker support in the interaction between workplace happiness and innovative work behavior içinde management and organization: Various approaches (Ed. Yasin Çakırel) (153- 165). Peter Lang. Berlin.

Wang, Y. D. ve Yang, C. (2016). How appealing are monetary rewards in the workplace? A study of ethical leadership, love of money, happiness, and turnover intention. Social Indicators Research, 129(3), 1277-1290.

Wright, T. A. ve Staw, B. M. (1999). Further thoughts on the happy-productive worker. Journal of Organizational Behavior: The International Journal of Industrial, Occupational and Organizational Psychology and Behavior, 20(1), 31-34.

Wright, T. A., ve Staw, B. M. (1999). Affect and favorable work outcomes: Two longitudinal tests of the happy-productive worker thesis. Journal of Organizational Behavior, 20(1), 1-23.

Wrzesniewski, A., McCauley, C., Rozin, P., ve Schwartz, B. (1997). Jobs, careers, and callings: People's relations to their work. Journal of Research in Personality, 31(1), 21-33.

Youssef, C. M. ve Luthans, F. (2007). Positive organizational behavior in the workplace: The impact of hope, optimism, and resilience. Journal of Management, 33(5), 774-800. 
Zhang, Z. (2020). Isn't " 996" a good reason to quit? A cross-cultural study about the influence of work-life balance on turnover intention. (Unpublished Master Thesis). 1-126.

\section{Kaynakça Bilgisi / Citation Information}

Erhan, T. (2021). İşyeri mutluluğu: Bir kavram incelemesi. OPUSUluslararası Toplum Araştırmaları Dergisi, 17(38), 5686-5712. DOI: 10.26466/opus.883377 